\title{
The Impact of Workplace Bullying on Employees' Turnover Intention: The Role of Self-Esteem
}

\author{
Xiaohui Li, Xiaoqin Liu, Weizhen Chen \\ School of Business, Guangdong University of Foreign Studies, Guangzhou, China \\ Email: 505381026@qq.com
}

How to cite this paper: Li, X. H., Liu, X. Q., \& Chen, W. Z. (2020). The Impact of Workplace Bullying on Employees' Turnover Intention: The Role of Self-Esteem. Open Journal of Social Sciences, 8, 23-34. https://doi.org/10.4236/jss.2020.810003

Received: September 3, 2020

Accepted: September 27, 2020

Published: September 30, 2020

Copyright ( 2020 by author(s) and Scientific Research Publishing Inc. This work is licensed under the Creative Commons Attribution International License (CC BY 4.0).

http://creativecommons.org/licenses/by/4.0/

\section{(c) (i) Open Access}

\begin{abstract}
The purpose of this study is to investigate the role of self-esteem in the relationship between workplace bullying and turnover intention in China. Basing on 215 samples, this study examined the relationship among workplace bullying, self-esteem and employees' turnover intention. The results show that: self-esteem is negatively related to the probability of reporting oneself as a target of workplace bullying; workplace bullying is an excellent predictor of employees' turnover; self-esteem plays a moderating role in the relationship between workplace bullying and turnover intention. An improved understanding of how individual differences impact on the exposure to workplace bullying and on the relationship between workplace bullying and turnover intention may have important implications from both the theoretical and the practical standpoints.
\end{abstract}

\section{Keywords}

Workplace Bullying, Self-Esteem, Turnover Intention, Moderating Role, Antecedents of Workplace Bullying

\section{Introduction}

Workplace bullying is broadly recognized to be a widespread and serious problem nowadays. It has been estimated that about $15 \%$ of workers on a global basis are targets of systematic bullying behaviors, and $11 \%$ perceive themselves as victims of bullying (Nielsen, Matthiesen, \& Einarsen, 2010). Many countries, including China, have increasingly been focusing on raising awareness and preventing this particular problem in order to prevent its negative effects on the victim's health and work performance as well as on the organization itself. 
Studies have been conducted to explore factors that contribute to bullying. Throughout the literature, there are two main research approaches to the understanding of the antecedents of workplace bullying. The first approach is the work environment hypothesis (Leymann, 1996). According to the work environment hypothesis, workplace bullying is the result of poor psychosocial working conditions such as occupational stressors (Bowling \& Beehr, 2006), adverse work characteristics (Broeck, Baillien, \& Witte, 2011) and excessive workload and time pressure (Ekici \& Beder, 2014). The second approach, known as the individual dispositions hypothesis, regards employees' individual characteristics, such as personality traits, as potential precursors of bullying (Einarsen, Hoel, Zapf, \& Cooper, 2010). Research findings suggest that in comparison with the oppressors and non-victims, the target group scores higher on neuroticism, depression (Dieter, 1999) and negative affectivity (Bowling, Beehr, Bennett, \& Watson, 2010), lower on emotional stability, aggressiveness, as well as on extraversion and assertiveness (Glasø, Matthiesen, Nielsen, \& Einarsen, 2010).

Although there is some research on individual dispositions and bullying, the work environment hypothesis has been the dominating framework and has received substantial empirical support in the last decade. By comparison, there is a lack of empirical findings on how individual dispositions actually are related to bullying (Nielsen \& Knardahl, 2015). Moreover, the finite existing research results are inconsistent. Some argue that the personality of targets can explain their exposure to bullying (Coyne, Seigne, \& Randall, 2000), some believe that individual dispositions are outcomes rather than causes of bullying (Glas $\varnothing$, Matthiesen, Nielsen, \& Einarsen, 2007), and others disregard the role played by targets' personal factors (Leymann, 1996). This reflects the still blurred state of findings about individual antecedents of workplace bullying. It is therefore crucial to conduct more research on the relationship between individual characteristics and bullying.

The victim of such negative acts may choose to quit because of the adverse nature of the working conditions in which bullying occurs. Previous research has provided evidence suggesting that exposure to workplace bullying is linked to employees intention or decision to leave (Coetzee \& Van Dyk, 2017). However, it has also been shown that some victims of bullying are more vulnerable than others (Berge \& Ståle, 2004). This indicates that responses to workplace bullying may be moderated by employees' personal characteristics. It is clear that personal characteristics may influence the way employees perceive and deal with workplace bullying, as well as the outcomes that result from this experience (Francioli et al., 2016), but empirical studies are rare.

In this study we focus on a specific individual characteristic, that is self-esteem, one of the main variables of personality traits and aim to investigate whether self-esteem can predict exposure to workplace bullying. Moreover, we argue that self-esteem may operate as a significant moderator in the relationship between the exposure to workplace bullying and turnover intention. As little research explores workplace bullying in China in general, or its relationships with individu- 
al characteristics and turnover intention, it is essential to establish that these relationships do indeed exist in the China context. An improved understanding of workplace bullying and how individual differences impact on workplace bullying may improve the theoretical knowledge. In addition, it may provide useful elements to enhance the design of interventions aimed at combating the phenomenon. So, this thesis has its necessity and practical significance.

\section{Theory and Hypothesis}

\subsection{Workplace Bullying and Turnover Intention}

Workplace bullying is a problem prevalent in contemporary working life. According to Einarsen, Hoel, Zapf, and L (2003), workplace bullying is defined as "harassing, offending, socially excluding someone or negatively affecting someone's work". To label something bullying it has to occur repeatedly, continuously and come from one or more persons, and the bullied have difficulties getting rid of this negative situation or defending himself/herself (Einarsen \& Skogstad, 1996).

Employees' turnover intention is defined as a conscious and deliberate willingness to leave the organization (Tett \& Meyer, 1993) and is potentially a sound predictor of actual turnover behaviors. Employees leave their jobs for a variety of reasons. One of the important reasons is work related stress (Elçi, Şener, Kürü, \& Alpkan, 2012).

Workplace bullying is a painful and aversive experience which has a negative impact on the bullied and even on the bystanders. Studies have shown bullying as a major stressor with detrimental consequences for psychology, emotion, health and well-being (Sultana, Sarker, \& Prodhan, 2017). People exposed to long term and persistent workplace bullying have been reported to demonstrate anxiety, suspicious, depression, and suffer from headache, fatigue and sleep disturbance. What's more, individuals experiencing workplace bullying are more likely to impair their confidence (Leisy \& Ahmad, 2016), inhibit collegiality and cooperation (Ekici \& Beder, 2014), decrease their job satisfaction (Jiang, Jiao, \& Rong, 2012), increase employees' depression, make one or more serious work errors (Paice \& Smith, 2009), as well as experiencing social isolation and stigmatization (Johnson, 2010). Steele, Rodgers, and Fogarty (2020) pointed that the correlations between bullying and psychological distress, job satisfaction, and affective commitment are all significant and for some outcomes greater than those involving the traditional job stressors.

When strain causes negative emotions and cognitions, one way to cope with this undesirable experience is emotional and physical withdrawal from the negative situation (Nathan, Jeffery, \& Marcie, 2007). For the individual, withdrawing from the situation can represent an adaptive response to avoid the pain associated with bullying and a form of self-defense. For members of organizations, withdrawal can be manifested in thoughts and behaviors associated with planning to leave the organization. Thinking about leaving is re- 
flected in turnover intentions (Ferris et al., 2008). We, therefore, propose the following hypothesis:

H1: Workplace bullying has a significant positive impact on employees' turnover intention.

\subsection{Self-Esteem and Workplace Bullying}

Rosenberg (1965) stated that self-esteem is an overall judgment that leads to an individual's self-worth, self-respect, and self-acceptance. Self-esteem is one of psychology's most polarizing constructs. Individuals with higher self-esteem are more likely to be confident in their ability than those with lower self-esteem (Schwarz \& Clore, 2007). They think more positively about themselves, have clearer and more certain self-concepts (Campbell \& Lavallee, 1993) and suffer less emotional distress when they encounter unexpected outcomes (Brown, 2010). So, people high in self-esteem are more likable and attractive, have better relationships, and make better impressions on others than people with low self-esteem. People with low self-esteem, who are normally hesitant to self-disclose and who have difficulty maintaining satisfying relationships, may be more likely to experience rejection and become a target or victim of bullying. On the other hand, low-self-esteem people feel worse about themselves in general than do high-self-esteem people (Brown, 2010). The negative perceptions mechanism suggests that certain individual dispositions are associated with a lowered threshold for interpreting behaviors as harassing. That means employees with such negative perceptions therefore have a higher risk than others for labelling negative events at the workplace as bullying. We, therefore, propose the following hypothesis:

H2: Lower self-esteem will predict exposure to workplace bullying.

Personality traits affect the way individuals typically appraise external negative stimuli and cope with them (Semmer, Grebner, \& Elfering, 2003). Workplace bullying is a typical negative stimulus. High self-esteem people make more self-serving attributions for negative outcomes than do people who are low in self-esteem (Stone-Romero \& Stone, 2002). That is, negative outcomes lead high-self-esteem participants to feel bad in general, but not bad about themselves, while lead low-self-esteem participants to feel bad in general and bad about themselves. Negative experiences may be less detrimental for individuals with high self-esteem because of the certainty they have regarding their positive characteristics. High self-esteem people, who have a positive evaluation of themselves, believe that workplace bullying is only an isolated event that indicates I just lack a chance, and will not happen in a new environment. And They are confident in the future and have a firm belief that their effort will pay off. So, they escape emotional distress quickly and start something new. While low Self-esteem individuals who are negative evaluation of themselves, feel ashamed and humiliated of themselves when bullying happening. To low-self-esteem person, being bullied means "I am a bad person". They believe that it is meaningless to change to a new environment because their ability and value will not 
change or improve. So, they tend to endure workplace bullying and its negative consequences. We, therefore, propose the following hypothesis:

H3: self-esteem plays a moderating role in the influence of workplace bullying on employee turnover intention. Individuals with high self-esteem have stronger turnover intention than those with low self-esteem when confronted with workplace bullying.

\section{Research Methods}

\subsection{Measures}

1) Workplace bullying: The measure was designed by Chinese scholars Li, Nie, Li, Wang, and Zhao (2011) who believe that workplace bullying is a three dimension construct (i.e. Personal attack, attack through work tasks and exclusion) in China. Cronbach' $\alpha=0.893$.

2) Turnover intention: The measure was designed by Scott et al. (1999), including items such as "I would prefer another more ideal job than the one I now work in." Cronbach' $\alpha=0.862$.

3) Self-esteem scale (SES) developed by Rosenberg was used in this study. There are 10 questions in the scale, such as "I think I have many advantages", Cronbach' $\alpha=0.817$.

The above variables were measured using five-point Likert scale ranging from 1 (strongly disagree) - 5 (strongly agree). In addition, this study took age, gender, education and working life as control variables.

\subsection{Procedure and Sample}

This study has carried out three questionnaires in China. The first time we completed the work of distributing and collecting questionnaires was in Guangzhou. The total number of the questionnaires distributed was 80, and the actual number of the collected questionnaires was 73 . After disregarding 5 unqualified questionnaires, there were 68 questionnaires left and the effective response rate was $85 \%$. For the second time, we took an online survey. A total of 120 questionnaires were collected. After removing the invalid questionnaires, 110 valid questionnaires remained. 45 questionnaires were distributed for the third time to a small enterprise, and 37 valid questionnaires were recovered and the effective recovery rate reached $82 \%$. The data collection process took 3 weeks and finally, 215 questionnaires were collected.

In the samples we collected, $1.8 \%$ were under 20 years of age, $84.1 \%$ were between 21 and 30 years of age, $8.4 \%$ were between 31 and 40 years of age, 5.7\% were over 40 years old; males accounted for $47 \%$ and females accounted for $53 \%$; $28.3 \%$ of the participants were junior college or below, $66.4 \%$ were undergraduate and 5.3\% were master's degree or above; State-owned enterprises, private enterprises, joint ventures and other enterprises accounted for $37.2 \%, 19.9 \%$, $14.3 \%$ and $28.6 \%$ respectively; while 20.2 percent of the participants worked between six months and one year, $30.7 \%$ for more than one year and less than 
three years, and $49.1 \%$ for more than three years.

\section{Results}

\subsection{Common Method Deviation Test and Confirmatory Factor Analysis}

We took three different data collecting methods that alleviated the potential common method bias of this study. In addition, we promoted Harman's one-factor test and results showed that the first factor was below 50 percent threshold and explained 26.269 percent of variance, indicating low concerns of the common method bias problem.

Confirmatory factor analysis was conducted to evaluate the distinctiveness and convergence of the variables. As can be seen from Table 1, the hypothesized three-factor model demonstrates a more acceptable fit to the data than other models. Results show that these three variables have good discriminant validity.

\subsection{Descriptive Statistics}

Means, standard deviations and reliabilities of variables involved in this paper are presented in Table 2. As can be seen from Table 2, there is a significant positive correlation coefficient of $0.443(P<0.01)$ between workplace bullying and turnover intention, showing that the higher the sense of being bullied, the higher intentions to leave the organization. $\mathrm{H} 1$ is initially validated. In addition, self-esteem and workplace bullying have a significant correlation, and the correlation coefficient is $-0.167, P<0.05$, showing that low levels of self-esteem are

Table 1. Confirmatory factor analysis. $(\mathrm{N}=215)$.

\begin{tabular}{ccccccccc}
\hline Model & $\mathrm{X}$ & $\mathrm{DF}$ & $\mathrm{X}^{2} / \mathrm{df}$ & $\mathrm{CFI}$ & $\mathrm{TLI}$ & $\mathrm{RMSEA}$ & $\mathrm{IFI}$ & SRMR \\
\hline 1. (1) + (2) + (3) & 216.740 & 9 & 24.082 & 0.561 & 0.268 & 0.320 & 0.566 & 0.1545 \\
2. (1) + (3), (2) & 168.729 & 8 & 21.091 & 0.660 & 0.363 & 0.299 & 0.6657 & 0.1233 \\
3. (1) (2) + (3) & 64.233 & 8 & 8.029 & 0.811 & 0.777 & 0.177 & 0.883 & 0.1143 \\
4. (1) + (2), (3) & 60.776 & 8 & 7.597 & 0.888 & 0.791 & 0.171 & 0.890 & 0.1060 \\
5. (1) (2), (3) & 10.847 & 6 & 1.808 & 0.990 & 0.974 & 0.060 & 0.990 & 0.0448
\end{tabular}

Note: (1) workplace bullying, (2) self-esteem, (3) turnover intention, “+” is a combination of representatives as a factor.

Table 2. Describe statistics and related analysis.

\begin{tabular}{lccccc}
\hline & $\mathrm{M}$ & $\mathrm{SD}$ & 1 & 2 & 3 \\
\hline 1) Workplace Bullying & 1.77 & 0.63 & 1 & & \\
2) Self-esteem & 2.90 & 0.44 & $-0.167^{*}$ & 1 & 1 \\
3) Turnover intention & 3.11 & 1.10 & $0.443^{* *}$ & -0.013 & \\
\hline
\end{tabular}

Notes: ${ }^{\star} P<0.05,{ }^{\star *} P<0.01$. 
prospectively related to victimization from workplace bullying. $\mathrm{H} 2$ is initially validated. Self-esteem correlated insignificantly with turnover $(\mathrm{r}=-0.013 ; P>$ 0.05). The result lay the foundation for the follow-up moderating test.

\subsection{Regression Analysis and Hypothetical Test}

To test H1-H3, we used the method proposed by Chinese scholars Wen, Hau, and Chang (2005). IBM SPSS Statistics Version 22 was used to analyze the data obtained from the questionnaire and the results of the test are presented in $\mathrm{Ta}$ ble 3.

In Model 4, workplace bullying is positively related to turnover intention $(\mathrm{b}=$ $0.736, p<0.001)$ indicating that exposure to workplace bullying will increase the intention to leave the organization. Therefore, $\mathrm{H} 1$ is supported.

In Model 2, data show that self-esteem is significantly negatively related to workplace bullying ( $b=-0.251, p<0.05)$, which means low self-esteem may increase the risk of being a target or victim of bullying. Therefore, H2 is supported.

In Model 5, the cross-term of workplace bullying and self-esteem is entered into the regression equation and the coefficient is significant $(b=0.575, p<0$. 05 ), indicating that the relationship of workplace bullying and turnover intention is moderated by self-esteem. H3 is supported.

Figure 1 illustrates the moderating effect of self-esteem. As can be seen, the slope of high self-esteem group is higher than that of low self-esteem group, indicating that self-esteem enhances the positive explanation of the relationship between workplace bullying and employee turnover intention. Employees with high self-esteem are more likely to leave the organizations than employees with low self-esteem are. $\mathrm{H} 2$ is further verified.

Table 3. Hierarchical regression analysis.

\begin{tabular}{cccccc}
\hline & \multicolumn{2}{c}{ Dependent: workplace bullying } & \multicolumn{2}{c}{ Dependent: turnover intention } \\
\cline { 2 - 6 } & Model 1 & Model 2 & Mode3 & Model 4 & Model 5 \\
\hline Gender & -0.157 & -0.158 & -0.036 & 0.079 & 0.110 \\
Age & -0.192 & -0.193 & $-0.534^{* *}$ & $-0.392^{*}$ & -0.367 \\
Education & 0.014 & 0.034 & -0.033 & -0.043 & -0.053 \\
Seniority & 0.047 & 0.068 & 0.010 & -0.024 & -0.051 \\
Nature of the corporate & -0.025 & -0.025 & -0.030 & -0.012 & -0.010 \\
Self-esteem & & $-0.251^{*}$ & & & 0.284 \\
Workplace bullying (WB) & & & & $0.736^{* * *}$ & $0.799^{* * *}$ \\
WB $\times$ Self-esteem & & & & & $0.575^{*}$ \\
$\mathrm{R}^{2}$ & 0.032 & 0.060 & 0.082 & 0.254 & 0.284 \\
$\mathrm{~F}$ & 1.453 & $2.311^{*}$ & $3.912^{* *}$ & $12.455^{* * *}$ & $10.762^{* * *}$ \\
$\Delta \mathrm{R}^{2}$ & 0.132 & 0.028 & 0.082 & 0.173 & 0.030 \\
\hline
\end{tabular}

Notes: ${ }^{*} p<0.05,{ }^{* *} p<0.01,{ }^{* * *} p<0.001$. 


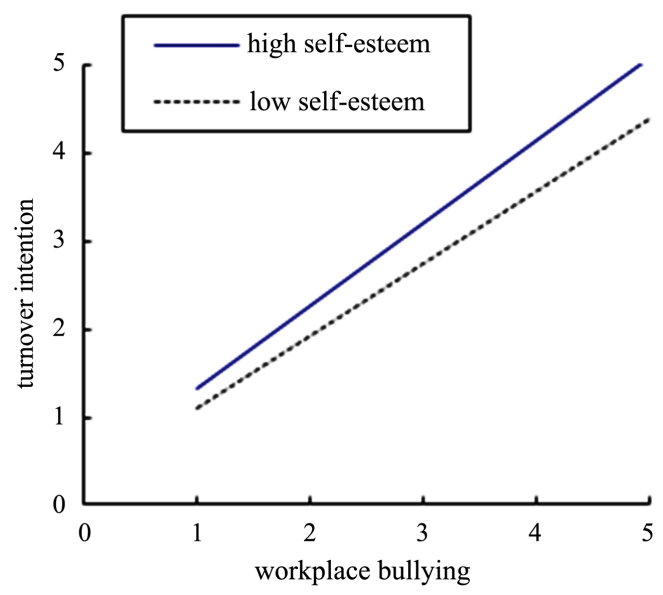

Figure 1. Moderating effect of self-esteem.

\section{Discussion and Conclusion}

The overarching objective of this study is to determine the role self-esteem plays in workplace bullying. The results show that lower self-esteem is associated with an increased risk of exposing to workplace bullying, and self-esteem also plays a moderating role in the influence of workplace bullying on employee turnover intention.

\subsection{Theoretical Implications}

This study contributes to the limited research regarding workplace bullying in the Chinese context by quantifying the links between workplace bullying, self-esteem and turnover intention.

Data show that workplace bullying has a significant positive impact on turnover intention. This confirms the results of several previous studies (Berthelsen, Skogstad, Lau, \& Einarsen, 2011; Schalkwyk, Els, \& Rothmann, 2011). Furthermore, turnover intention has been found to be a significant predictor of turnover behavior, which has substantial cost implications for the organization such as a low staff satisfaction, sickness absence, workers compensation and reduced productivity. In other words, workplace bullying is a worldwide concern with devastating effects on both the targets and organizations.

Self-esteem is an important personality variable. People with low self-esteem are expected to possess poorer coping abilities and a less resistant personality, which would lead them to be particularly prone to become targets of workplace bulling. In this study we indeed found that those who were deemed victims of workplace bullying exhibited lower levels of self-esteem, which aligns with studies observing that personal dimensions play a significant role in the occurrence of workplace bullying (Bowling et al., 2010; Matthiesen \& Einarsen, 2007).

Another objective of this study was to determine whether self-esteem moderates the relationship between workplace bullying and turnover intention. The results confirmed this moderating effect. Just as Brown (2010) pointed out 
that failure means something different to a low-self-esteem person than to a high-self-esteem person. To a high-self-esteem person, failure indicates "I lack some ability or chance," to a low-self-esteem person, failure means "I am a bad person". Therefore, a person with high-self-esteem is more willing to leave the company, find a new job, set higher goals for himself, and try different things, but a person with low-self-esteem is more likely to choose to stay and endure.

\subsection{Practical Implications}

Workplace bullying is broadly recognized to be a serious problem nowadays, with serious consequences for the employees, the organizations, and the society at large. Effective interventions are needed to stop workplace bullying that contributes to high rates of turnover intention. Awareness also needs to be raised about what constitutes bullying behavior. We find that low self-esteem is associated with a higher probability of reporting oneself as a target of workplace bullying, hence, regular screening for such negative affectivity should be done to enable early intervention.

\subsection{Limitations and Extensions}

First, the survey sample size is not large enough, and concentrated on the Pearl River Delta region in China. Future research should adopt a wider perspective and include more data from different industry, different fields and different population. Second, the way to get the data too limited, basic from employee self-report questionnaire, and based on the analysis of firms' cross-sectional data, where the time lag has not been adequately addressed. Future research might consider including data from paired questionnaire, and collecting longitudinal data of samples rather than the cross-sectional data. Future research could also focus on identifying the cause-effect relations between personality dispositions and exposure to bullying via a longitudinal study. Thirdly, although we examined personality characteristics of victims as potential correlates of workplace bullying, personality characteristics of both victims and perpetrators are likely to play a role in bullying. Future research should examine the relative influences of victims' and perpetrators' personality characteristics in predicting workplace bullying.

\section{Project}

The phased achievement of the project supported by the National Social Science Fund of China (Grant No. 17BGL095).

The achievement of the project supported by Guangdong University of Foreign Studies (Grant No. 15Q27; 299-GK19G057).

\section{Conflicts of Interest}

The authors declare no conflicts of interest regarding the publication of this paper. 


\section{References}

Berge, M. S., \& Ståle, E. (2004). Psychiatric Distress and Symptoms of PTSD among Victims of Bullying at Work. British Journal of Guidance and Counselling, 32, 335-356. https://doi.org/10.1080/03069880410001723558

Berthelsen, M., Skogstad, A., Lau, B. R., \& Einarsen, S. L. (2011). Do They Stay or Do They Go? International Journal of Manpower, 32, 178-193.

https://doi.org/10.1108/01437721111130198

Bowling, N. A., \& Beehr, T. A. (2006). Workplace Harassment from the Victim's Perspective: A Theoretical Model and Meta-Analysis. The Journal of Applied Psychology, 91, 998-1012. https://doi.org/10.1037/0021-9010.91.5.998

Bowling, N. A., Beehr, T. A., Bennett, M. M., \& Watson, C. P. (2010). Target Personality and Workplace Victimization: A Prospective Analysis. Work \& Stress, 24, 140-158. https://doi.org/10.1080/02678373.2010.489635

Broeck, A. V. D., Baillien, E., \& Witte, H. D. (2011). Workplace Bullying: A Perspective from the Job Demands-Resources Model. South African Journal of Industrial Psychology, 37, 40-51. https://doi.org/10.4102/sajip.v37i2.879

Brown, J. D. (2010). High Self-Esteem Buffers Negative Feedback: Once More with Feeling. Cognition \& Emotion, 24, 1389-1404. https://doi.org/10.1080/02699930903504405

Campbell, J. D., \& Lavallee, L. F. (1993). Who Am I? The Role of Self-Concept Confusion in Understanding the Behavior of People with Low Self-Esteem. In R. F. Baumeister (Ed.), Self-Esteem. The Plenum Series in Social/Clinical Psychology (pp. 3-20). Boston, MA: Springer. https://doi.org/10.1007/978-1-4684-8956-9 1

Coetzee, M., \& Van Dyk, J. (2017). Workplace Bullying and Turnover Intention: Exploring Work Engagement as a Potential Mediator. Psychological Reports, 121, 375-392. https://doi.org/10.1177/0033294117725073

Coyne, I., Seigne, E., \& Randall, P. J. (2000). Predicting Workplace Victim Status from Personality. European Journal of Work \& Organizational Psychology, 9, 335-349. https://doi.org/10.1080/135943200417957

Dieter, Z. (1999). Organisational, Work Group Related and Personal Causes of Mobbing/Bullying at Work. International Journal of Manpower, 20, 70-85. https://doi.org/10.1108/01437729910268669

Einarsen, S., Hoel, Zapf, D., \& L, C. C. (2003). The Concept of Bullying at Work: The European Tradition. Isla De Arriarán Revista Cultural Y Científica, 63, 175-212.

Einarsen, S., Hoel, H., Zapf, D., \& Cooper, C. (2010). The Concept of Bullying and Harassment at Work: The European Tradition. London: Taylor \& Francis. https://doi.org/10.1201/EBK1439804896-3

Einarsen, S. L., \& Skogstad, A. (1996). Bullying at Work: Epidemiological Findings in Public and Private Organizations. European Journal of Work \& Organizational Psychology, 5, 185-201. https://doi.org/10.1080/13594329608414854

Ekici, D., \& Beder, A. (2014). The Effects of Workplace Bullying on Physicians and Nurses. Australian Journal of Advanced Nursing, 31, 24-33.

Elçi, M., Şener, İ., Kürü, S. A., \& Alpkan, L. (2012). The Impact of Ethical Leadership and Leadership Effectiveness on Employees' Turnover Intention: The Mediating Role of Work Related Stress. Procedia-Social and Behavioral Sciences, 58, 289-297. https://doi.org/10.1016/j.sbspro.2012.09.1003

Francioli, L., Høgh, A., Conway, P. M., Costa, G., Karasek, R., \& Hansen, Å. M. (2016). Do Personal Dispositions Affect the Relationship between Psychosocial Working Conditions and Workplace Bullying? Ethics Behavior, 26, 451-469. 
https://doi.org/10.1080/10508422.2015.1043367

Glas Ø, L., Matthiesen, S. B., Nielsen, M. B., \& Einarsen, S. (2007). Do Targets of Workplace Bullying Portray a General Victim Personality Profile? Scandinavian Journal of Psychology, 48, 313-319. https://doi.org/10.1111/j.1467-9450.2007.00554.x

Glasø, L., Matthiesen, S. B., Nielsen, M. B., \& Einarsen, S. (2010). Do Targets of Workplace Bullying Portray a General Victim Personality Profile? Scandinavian Journal of Psychology, 48, 313-319. https://doi.org/10.1111/j.1467-9450.2007.00554.x

Jiang, J., Jiao, D., \& Rong, W. (2012). Workplace Bullying, Employees' Depression and Job Satisfaction: Moderating Effect of Coping Strategies. Chinese Mental Health Journal, 26, 610-615.

Johnson, S. L. (2010). International Perspectives on Workplace Bullying among Nurses: A Review. International Nursing Review, 56, 34-40. https://doi.org/10.1111/j.1466-7657.2008.00679.x

Ferris, L., Brown, D. J., Berry, J. W., \& Lian, H. W. (2008). The Development and Validation of the Workplace Ostracism Scale. Journal of Applied Psychology, 93, 1348-1366. https://doi.org/10.1037/a0012743

Leisy, H. B., \& Ahmad, M. J. (2016). Altering Workplace Attitudes for Resident Education: Discovering Solutions for Medical Resident Bullying through Literature Review. BMC Medical Education, 16, 127. https://doi.org/10.1186/s12909-016-0639-8

Leymann, H. (1996). The Content and Development of Mobbing at Work. European Journal of Work and Organizational Psychology, 5, 165-184.

https://doi.org/10.1080/13594329608414853

Li, Y., Nie, G., Li, Y., Wang, M., \& Zhao, G. (2011). The Structure and Measurement of Workplace Bullying in China. Psychological Science, 34, 1201-1208.

Matthiesen, S. B., \& Einarsen, S. L. (2007). Perpetrators and Targets of Bullying at Work: Role Stress and Individual Differences. Violence and Victims, 22, 735-753. https://doi.org/10.1891/088667007782793174

Nathan, P. P., Jeffery, A. L., \& Marcie, A. L. (2007). Differential Challenge Stressor-Hindrance Stressor Relationships with Job Attitudes, Turnover Intentions, Turnover, and Withdrawal Behavior: A Meta-Analysis. The Journal of Applied Psychology, 92, 438-454. https://doi.org/10.1037/0021-9010.92.2.438

Nielsen, M. B., \& Knardahl, S. (2015). Is Workplace Bullying Related to the Personality Traits of Victims? A Two-Year Prospective Study. Work \& Stress: An International Journal of Work, Health \& Organisations, 29, 128-149. https://doi.org/10.1080/02678373.2015.1032383

Nielsen, M. B., Matthiesen, S. B., \& Einarsen, S. (2010). The Impact of Methodological Moderators on Prevalence Rates of Workplace Bullying. A Meta-Analysis. Journal of Occupational and Organizational Psychology, 83, 955-979. https://doi.org/10.1348/096317909X481256

Paice, E., \& Smith, D. (2009). Bullying of Trainee Doctors Is a Patient Safety Issue. The Clinical Teacher, 6, 13-17. https://doi.org/10.1111/j.1743-498X.2008.00251.X

Rosenberg, M. (1965). The Measurement of Self-Esteem. In Society and the Adolescent Self-Image (pp. 16-36). Princeton, NJ: Princeton University Press.

https://doi.org/10.1515/9781400876136

Schalkwyk, L.-M. V., Els, C., \& Rothmann, I. (2011). The Moderating Role of Perceived Organisational Support in the Relationship between Workplace Bullying and Turnover Intention across Sectors in South Africa. Journal of Human Resource Management, 9, a384. https://doi.org/10.4102/sajhrm.v9i1.384 
Schwarz, N., \& Clore, G. L. (2007). Feelings and Phenomenal Experiences. New York: The Guilford Press.

Scott, C. R., Connaughton, S. L., Diaz-Saenz, H. R., Maguire, K., Ramirez, R., Richardson, B., Morgan, D. et al. (1999). The Impacts of Communication and Multiple Identifications on Intent to Leave: A Multimethodological Exploration. Management Communication Quarterly, 12, 400-435. https://doi.org/10.1177/0893318999123002

Semmer, N., Grebner, S., \& Elfering, A. (2003). Beyond Self-Report: Using Observational, Physiological, and Situation-Based Measures in Research on Occupational Stress. Bingley: Emerald Group Publishing Limited.

Steele, N. M., Rodgers, B., \& Fogarty, G. J. (2020). The Relationships of Experiencing Workplace Bullying with Mental Health, Affective Commitment, and Job Satisfaction: Application of the Job Demands Control Model. International Journal of Environmental Research and Public Health, 17, 2151. https://doi.org/10.3390/ijerph17062151

Stone-Romero, E. F., \& Stone, D. L. (2002). Cross-Cultural Differences in Responses to Feedback: Implications for Individual, Group, and Organizational Effectiveness. Research in Personnel \& Human Resources Management, 21, 275-331.

https://doi.org/10.1016/S0742-7301(02)21007-5

Sultana, A., Sarker, M. N. I., \& Prodhan, A. S. (2017). Job Satisfaction of Public and Private Primary School Teachers of Bogra District in Bangladesh. Journal of Sociology and Anthropology, 1, 41-46.

Tett, R. P., \& Meyer, J. P. (1993). Job Satisfaction, Organizational Commitment, Turnover Intention, and Turnover: Path Analyses Based on Meta-Analytic Findings. Personnel Psychology, 46, 259-293. https://doi.org/10.1111/j.1744-6570.1993.tb00874.x

Wen, Z. L., Hau, K.-T., \& Chang, L. (2005). A Comparison of Moderator and Mediator and Their Applications. Acta Psychologica Sinica, 37, 268-274. 